\title{
Genetic composition of Atlantic and Mediterranean recruits of European eel Anguilla anguilla based on EST-linked microsatellite loci
}

\author{
J. M. Pujolar*†, G. A. De Leoł, E. Ciccotti§ and L. Zane† \\ $\dagger$ Dipartimento di Biologia, Università di Padova, Via G. Colombo 3, I-35131, Padova, Italy, \\ $\$$ Dipartimento di Scienze Ambientali, Università degli Studi di Parma, Parco Area delle Scienze \\ 11A, I-43100, Parma, Italy and §Dipartimento di Biologia, Università Roma Tor Vergata, I-00133, \\ Rome, Italy
}

\begin{abstract}
Anguilla anguilla glass eels arriving at two Mediterranean and two Atlantic sites were tested for differences in genetic composition between regions using a total of 23 microsatellite loci developed from an expressed sequence tag (EST) library. Hierarchical analysis of molecular variance indicated a non-significant difference between regions (Mediterranean $v$. Atlantic), which contrasted with the significant differences observed between samples within regions. The existence of a single spawning site for all A. anguilla individuals and extensive migration loop with great opportunity for mixing of individuals might explain the homogeneity in genetic composition found between regions. The observation of a (small-scale) pattern of genetic patchiness among intra-annual samples (arrival waves) within geographic regions does not conflict with the lack of (large-scale) geographic substructuring found between the Mediterranean and Atlantic regions, but most likely is a consequence of the strong dependence of A. anguilla on oceanic conditions in the Sargasso Sea that might result in a limited parental contribution to each spawning event. The comparison of Atlantic and Mediterranean A. anguilla glass eel recruits based on EST-linked microsatellite loci provides evidence supporting the hypothesis of panmixia A. anguilla across Europe.

(C) 2009 The Authors Journal compilation (C 2009 The Fisheries Society of the British Isles
\end{abstract}

Key words: arrival waves; genetic patchiness; genetic structure; panmixia.

\section{INTRODUCTION}

Genetic population structure can range from complete panmixia where each individual has an equal probability of reproducing with any other individual, to highly structured populations with complete reproductive isolation. Managing genetic diversity in marine organisms requires evaluation of the genetic structure and partitioning of stocks of a given species in order to infer the genetic implications of the loss of components. This holds particularly true in the case of the European eel Anguilla anguilla (L.), a species in which recruitment of glass eels has declined dramatically in recent decades (to $1 \%$ of early-1980s levels in some time series;

\footnotetext{
*Author to whom correspondence should be addressed. Tel.: +39 4982 76220; fax: +39 4982 76209; email: josemartin.pujolar@unipd.it
} 
ICES, 2008), jeopardizing the future of the species. Causes of this crash include anthropogenic factors such as overfishing, migration barriers (dams and hydroelectric power plants), habitat destruction, introduced diseases and parasites (ICES, 2008), as well as environmental factors such as climate and ocean current change (Knights, 2003; Friedland et al., 2007; Bonhommeau et al., 2008a, b; Kettle et al., 2008).

Anguilla anguilla is a facultatively catadromous species with a particularly complex life cycle, which moves between marine and continental environments. After spawning in the Sargasso Sea, larvae (leptocephali) cross the Atlantic Ocean and metamorphose into glass eels that complete the migration into continental growth habitats. Glass eels metamorphose into yellow eels and after an average of 7-8 years for males and 11 years for females metamorphose into silver eels that migrate back to the Sargasso Sea, where they reproduce once and die (Tesch, 2003).

While the existence of a single spawning ground could lead to individual mixing and homogenization of the gene pool, genetic differences between A. anguilla populations could occur if spawning sub-populations are separated spatially or temporally (A. anguilla shows a protracted spawning season; McCleave, 2008), followed by non-random larval dispersal (Kettle \& Haines, 2006). In this sense, panmixia in A. anguilla was widely accepted on the basis of early genetic studies (Dannewitz et al., 2005) until the independent studies of Wirth \& Bernatchez (2001), and Maes \& Volckaert (2002) suggested a weak but significant population structure following a pattern of isolation by distance (IBD). Nevertheless, Dannewitz et al. (2005) proved the IBD pattern to be unstable over time: when temporal replicates of the geographical sampling were included, hierarchical analysis revealed no significant genetic sub-structuring and hence no IBD. Recent studies focusing on the genetic composition of recruiting juveniles (A. anguilla glass eels) have prompted the panmixia hypothesis for this species to be reconsidered again. Using 12 polymorphic allozyme and six variable microsatellite loci, Pujolar et al. (2006, 2007) observed a pattern of genetic patchiness among intra-annual samples within cohorts (arrival waves), most likely originating from variable oceanic and climatic conditions. With the same markers, Maes et al. (2006) found a subtle but significant correlation between genetic and temporal distance, irrespective of geographical location, pointing to a pattern of isolation by time (IBT) between years, namely between spawning cohorts separated by 2-3 years. IBT on a broader scale and genetic patchiness on a local scale are not contradictory but a consequence of the catadromous life strategy of $A$. anguilla, leading to a large variance in reproductive success of adults.

A limitation of previous genetic studies on A. anguilla is the low number of markers used, with all recent studies being based on six to seven microsatellite loci (Wirth \& Bernatchez, 2001; Dannewitz et al., 2005; Maes et al., 2006; Pujolar et al., 2006, 2007). Another caveat is that a weak geographical differentiation at neutral loci (microsatellites) does not preclude the existence of more pronounced differences at loci affected by selection, which might lead to underestimating quantitative and adaptive differentiation between populations (Conover et al., 2006). Recently, Hemmer-Hansen et al. (2007) showed the existence of adaptive divergence despite high gene flow in the European flounder Platichthys flesus (L.) by contrasting the pattern of genetic structure at putatively neutral microsatellites with the pattern at the heat-shock cognate protein Hsc70. Similarly, O'Malley \& Banks (2008) found evidence of a latitudinal cline in average allele length on repeat motif variants of the Chinook salmon Oncorhynchus tshawytscha (Walbaum) Clock gene, suggesting 
that the observed variation may be maintained by selection and reflect adaptation to ecological factors.

To correct for the bias caused by a limited number of neutral markers, in the present study a total of 23 microsatellite loci were developed from expressed sequence tags (EST), which are single-read sequences produced from partial sequencing of a mRNA pool. EST-linked microsatellites have the advantage of being putative type I markers (non-neutral), as it is possible to connect the function of the transcript of the genes from an EST sequence with the presence of a microsatellite. In contrast, 'traditional' microsatellites obtained from enriched libraries are generally type II markers, which are not linked to genes of known function. It is likely that ecologically important traits have been shaped by natural selection, which means that examining patterns of molecular evolution in EST-linked microsatellites could provide a way of screening numerous genetic loci for signatures of adaptive evolution. The aim of the present study was to compare Atlantic and Mediterranean samples of A. anguilla glass eel in order to test for differences in genetic composition between regions. Genetic data are discussed in relation to available information on the biology and life history of the species that points to the possibility of the Mediterranean region comprising a different group, namely: (1) a significant heterogeneity in morphometric characters of A. anguilla glass eels including length, mass and condition (Boetius \& Boetius, 1989; Pujolar et al., 2007), with Mediterranean samples showing a significantly smaller size in comparison with Atlantic samples and (2) while the existence of a spawning ground in the Mediterranean Sea has been talked about but never proved (based on the observation of leptocephali off the strait of Messina; Grassi, 1896), Mediterranean A. anguilla glass eels show a different arrival period and putative migration route in comparison with the rest of European A. anguilla glass eels (Boetius \& Boetius, 1989; Kettle \& Haines, 2006).

\section{MATERIALS AND METHODS}

Anguilla anguilla glass eel samples were collected in January 2007 in a total of four separate geographic locations (Table I), two in the Mediterranean Sea: (1) samples from the estuary of the River Tiber (Tevere; see Table 1 for latitude and longitude) in the west coast of Italy (Tyrrhenian Sea) and (2) samples from the Laguna di Lesina in the east coast of Italy, a brackish lake connected to the Adriatic Sea, and two in the Atlantic Ocean: (3) samples from the estuary of the River Gironde in west France and (4) samples from the estuary of the River Vilaine in Brittany, north-west France.

Minute sections of tissue from ethanol-preserved fish were digested in a lysis buffer containing $100 \mu \mathrm{l}$ TE Buffer, $7 \mu \mathrm{l} 1 \mathrm{M}$ DTT (dithiothreitol) solution pH $5 \cdot 2$ (diluted in $0.08 \mathrm{M}$ $\mathrm{NaAC})$ and $2 \mu \mathrm{l}$ proteinase $\mathrm{K}$ solution $\left(20 \mathrm{mg} \mathrm{m}^{-1}\right)$ for at least $4 \mathrm{~h}$ at $56^{\circ} \mathrm{C}$. After incubation at $96^{\circ} \mathrm{C}$ for $10 \mathrm{~min}$, samples were centrifuged at $13600 \mathrm{~g}$ for $11 \mathrm{~min}$, and the supernatant was stored at $-20^{\circ} \mathrm{C}$.

Genotypes were examined at a total of 23 EST-linked microsatellite loci developed in A. anguilla after screening a database of c. 6000 EST that allowed the identification of 795 contigs and 4008 singletons (Pujolar et al. 2008). Microsatellites were grouped in two separate multiplexes in order to reduce polymerase chain reaction (PCR) and genotyping costs: multiplex 1 (AAN22D01, AAN24A09, AAN24L24, AAN26N13, AAN33D15, AAN35N10, AAN44B14, AAN44E05, AANCT070, AANCT202, AANCT446 and AANCT812); multiplex 2 (AAN03I14, AAN06E24, AAN22M07, AAN41A22, AAN41E24, AAN41F01, AAN42O08, AAN44B22, AANCT347, AANCT390 and AANCT859).

PCR products were obtained in a GeneAmp PCR System 2700 Thermocycler (Applied Biosystems; www.appliedbiosystems.com) using the Qiagen Multiplex PCR Kit. PCR 


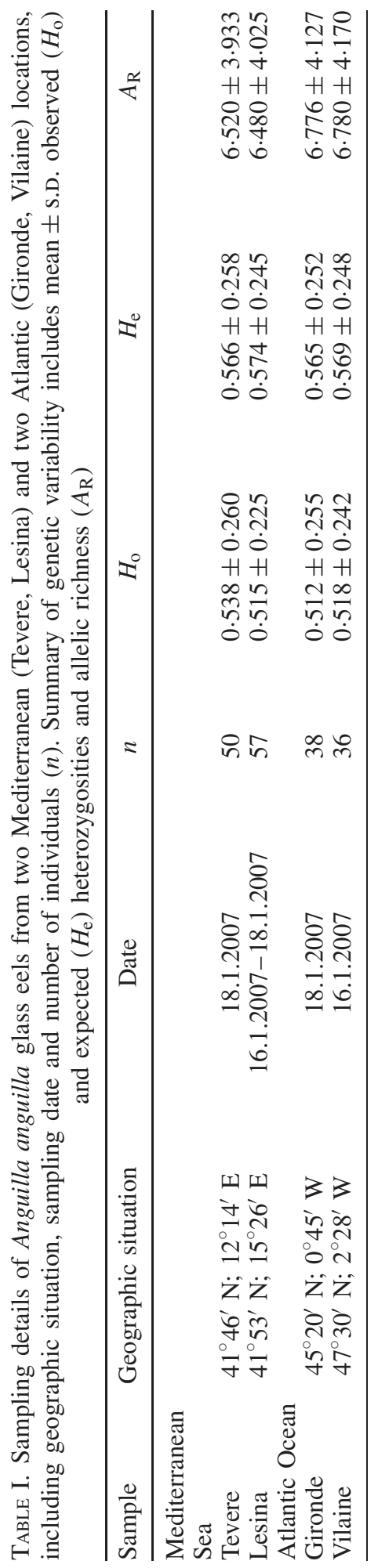


reactions consisted of $2 \mu 1$ template DNA, $5 \mu$ l Qiagen Multiplex PCR Master Mix, $0.2 \mu 1$ $10 \mu \mathrm{M}$ forward and reverse primers and water up to $10 \mu \mathrm{l}$. PCR conditions were as follows: $15 \mathrm{~min}$ at $95^{\circ} \mathrm{C}, 35$ cycles of $30 \mathrm{~s}$ at $94^{\circ} \mathrm{C}, 90 \mathrm{~s}$ at $57^{\circ} \mathrm{C}$ and $1 \mathrm{~min}$ at $72^{\circ} \mathrm{C}$, and final elongation for $30 \mathrm{~min}$ at $60^{\circ} \mathrm{C}$. PCR products were visualized in $1.8 \%$ agarose gels and screened for microsatellite polymorphism using an ABI 3130 AVANT automatic capillary sequencer (Applied Biosystems). Alleles were sized according to a Liz500 (50-500 bp) marker.

Within-sample genetic diversity statistics were assessed by observed $\left(H_{0}\right)$ and expected $\left(H_{\mathrm{e}}\right)$ heterozygosities per locus using GENETIX version 4.05 (Belkhir et al., 2005), and allelic richness $\left(A_{R}\right)$ using FSTAT (Goudet, 2002). Differences in genetic diversity among samples were tested by one-way ANOVA using STATISTICA version 6.0 (StatSoft Inc.; www.statsoft.com). Deviations from Hardy-Weinberg equilibrium (HWE), linkage disequilibrium and differences in allele and genotype frequencies among samples were tested using GENEPOP version 3.4 (Raymond \& Rousset, 1995). Presence of null alleles was tested using the programme MICRO-CHECKER version 2.2.3 (Van Oosterhout et al., 2004; www.microchecker.hull.ac.uk). Population structure was studied using non-hierarchical and hierarchical $F$-statistics (Weir \& Cockerman, 1984) calculated using ARLEQUIN (Schneider et al., 2000). Significance tests were assessed with 10000 permutation tests. In all cases, significance levels were corrected for multiple comparisons using Bonferroni (Rice, 1989). Pair-wise multilocus comparisons between samples were calculated by Cavalli-Sforza \& Edwards (1967) chord distance and a multivariate ordination was conducted by multidimensional scaling (MDS) analysis using STATISTICA version 6.0 (StatSoft).

Average relatedness of all individuals to each other $(r)$ within samples at 23 microsatellite loci was calculated using ML-Relate (Kalinowski et al., 2006). The significance of the values of relatedness was tested using 1000 permutations of alleles among individuals in order to calculate the proportion of pair-wise relatedness values attributable to significant half or full siblings compared to random sharing of alleles.

Finally, neutrality of the markers was tested using the software LOSITAN (Antao et al., 2008; http://www.popgen.eu/soft/lositan/), which implements a $F_{\mathrm{ST}}$ outlier detection approach. This method evaluates the relationship between $F_{\mathrm{ST}}$ and $H_{\mathrm{e}}$ in an island model, describing the expected distribution of Wright's (1931) inbreeding coefficient $F_{\mathrm{ST}} v . H_{\mathrm{e}}$ under an island model of migration with neutral markers. This distribution is used to identify outlier loci that show excessive high or low $F_{\mathrm{ST}}$ compared to neutral expectations. Such outlier loci are candidates for being subject to selection.

\section{RESULTS}

All samples showed similar levels of polymorphism (Table I), with observed heterozygosities ranging from 0.512 (Gironde) to 0.538 (Tevere), and expected heterozygosities ranging from 0.565 (Gironde) to 0.574 (Lesina). The value of allelic richness was highly similar in all samples, ranging from 6.48 (Lesina) to 6.78 (Vilaine). Comparisons of $H_{\mathrm{o}}, H_{\mathrm{e}}$ and $A_{\mathrm{R}}$ across samples using one-way ANOVA were statistically not significant (all $P>0.05$ ). All loci were in HardyWeinberg equilibrium except $A A N 41 A 22$, which showed a highly significant excess of homozygotes in all four samples $(P<0.001)$, which might be due to the presence of null alleles, as suggested by the software MICRO-CHECKER.

Half of the loci were moderately polymorphic (between four and nine alleles per locus), while 10 highly polymorphic ones exhibited between 11 and 20 alleles per locus, with the highest number of alleles found at locus AAN24A09 (37 alleles). Microsatellites consisting of di-nucleotide repeats showed a higher variation (mean \pm S.D $=15.08 \pm 7.82$ alleles) than tri-nucleotide (mean \pm S.D. $=6 \cdot 20 \pm 1.30$ alleles) and tetra-nucleotide (mean \pm s.D. $=5.60 \pm 1.52$ alleles) repeats. 
Comparison of allele frequencies among samples showed significant differences at two loci: AAN24A09 $(P=0.001)$, which is the locus with the highest number of alleles, and AAN41A22 $(P<0.001)$, which is the only locus not in HWE. Comparison of pooled Mediterranean $v$. Atlantic samples showed significant differences only at locus AAAN41A22 $(P<0.01)$.

Overall genetic differentiation was low $\left(F_{\mathrm{ST}}=0.00241\right)$ but significant $(P<$ $0 \cdot 05$ ), and most of the genetic variation was present within samples (Table II). Reexamination of the data excluding locus AAN41A22 (only locus not in HWE) showed a similar genetic differentiation. An AMOVA comparing Mediterranean and Atlantic samples showed that genetic differentiation partitioned significantly among samples within regions $\left(F_{\mathrm{SC}}=0.00209 ; P<0.05\right)$, while no significant differentiation was observed between regions $\left(F_{\mathrm{CT}}=0.00048 ; P>0.05\right)$. An AMOVA excluding locus AAN41A22 gave a comparable output (Table II).

Calculation of Cavalli-Sforza \& Edwards (1967) chord distance showed similar values between any pair of samples (0.017-0.023). A Principal component analysis showed no clear temporal or spatial grouping of samples.

Mean relatedness of all individuals to each other was low and similar across samples, ranging from 0.028 (Vilaine) to 0.036 (Tevere) (Table III). Despite the low values of average relatedness, half- and full-siblings were observed in all samples. The percentage of pair-wise relatedness values attributable to significant half-sib or full sib relationships compared to random sharing of alleles was slightly lower in the two Atlantic samples (Vilaine, 0.69\%; Gironde, $1.35 \%$ ) than in the Tevere $(2.35 \%)$ or Lesina $(2 \cdot 18 \%)$ ones.

Using LOSITAN, one out of 23 loci (AAN24A09) was identified as outlier, showing significant larger differences between locations than expected for a neutral locus $(P<0 \cdot 056)$. When combining the results from MICRO-CHECKER and LOSITAN, no differences were observed at locus AAN41A22 (the only locus not in HWE) either using the observed allele frequencies or when including the estimation of the frequency of the null alleles.

\section{DISCUSSION}

The fundamental result from this study is the lack of genetic differentiation observed between Mediterranean and Atlantic A. anguilla glass eels using a total

TABLE II. F-statistics from non-hierarchical and hierarchical (AMOVA) analyses of Anguilla anguilla samples. In the AMOVA analysis, genetic differentiation is partitioned into genetic differentiation among geographical regions (Mediterranean $v$. Atlantic) $\left(F_{\mathrm{CT}}\right)$, and genetic differentiation among samples within geographical regions $\left(F_{\mathrm{SC}}\right)$. The 22 loci analysis excludes locus $A A N 41 A 22$, not in Hardy-Weinberg equilibrium. $P$-values in parentheses

\begin{tabular}{lccc}
\hline Dataset & $n$ & $F$-statistic \\
\hline Non-hierarchical analysis & 171 & $0.00241(P<0.05)$ & \\
23 loci & 171 & $0.00218(P<0.05)$ & $F_{\text {ST }}$ \\
22 loci & & $F_{\mathrm{CT}}$ & $0.00209(P<0.05)$ \\
Hierarchical analysis & 171 & $P>0.05$ & $0.00178(P<0.05)$ \\
23 loci & 171 & & \\
22 loci &
\end{tabular}


TABLE III. Values of mean \pm S.D. and maximum relatedness $(r)$ within samples, including percentage of pair-wise relatedness values attributable to significant half-sibs or full-sibs compared to random sharing of alleles

\begin{tabular}{lccc}
\hline & \multicolumn{3}{c}{$r$} \\
\cline { 2 - 4 } Sample & Per cent half or full sibs & Mean \pm S.D. & Maximum $r$ \\
\hline Mediterranean & 2.35 & $0.036 \pm 0.061$ & 0.462 \\
Tevere & 2.18 & $0.031 \pm 0.058$ & 0.960 \\
Lesina & & & \\
Atlantic & 1.35 & $0.032 \pm 0.059$ & 0.410 \\
Gironde & 0.69 & $0.028 \pm 0.054$ & 0.386 \\
Vilaine & & & \\
\hline
\end{tabular}

of 23 EST-linked microsatellite loci, which is the largest survey to date considering number of loci used, and also the first study to use putative selected microsatellites. Hierarchical analysis of molecular variance indicated a non-significant differentiation between regions (Mediterranean Sea $v$. Atlantic Ocean) that contrasted with a significant differentiation between samples within regions. The proportion of total genetic variance explained by differences within regions was at least five-fold higher than the proportion explained by differences between regions. Furthermore, no differences were found in allelic frequencies either across all samples or when comparing pooled Mediterranean Sea $v$. Atlantic Ocean samples, and genetic distances were similar between any pair of samples.

The results using putatively selected EST-linked microsatellites showed comparable results to previous studies using neutral genomic microsatellites with regard to population differentiation and sub-structuring. Nevertheless, notable differences were observed regarding patterns of genetic variability, which suggest that the markers used did not behave like neutral ones. In this sense, the studies of Maes et al. (2006) and Pujolar et al. (2006) using six neutral genomic microsatellites showed higher heterozygosities $\left(H_{\mathrm{e}}=0.701-0.752\right.$ : Maes et al., 2006; $H_{\mathrm{e}}=0.702-0.747$ : Pujolar et al., 2006; $H_{e}=0.565-0.574$ : this study) and a two-fold higher allelic richness $\left(A_{\mathrm{R}}=11 \cdot 70-13 \cdot 65\right.$ : Maes et al., 2006; $A_{\mathrm{R}}=10 \cdot 16-11 \cdot 12$ : Pujolar et al. 2006; $A_{\mathrm{R}}=6.48-6 \cdot 78$ : this study). Genomic microsatellites typically show a higher number of alleles, with all loci in Pujolar et al. (2006) showing $>10$ alleles and a maximum of 60 alleles observed at locus Aro063, which contrasts with 13 out of 23 loci in the present study showing $<10$ alleles, with a mean \pm s.D. of $6 \cdot 20 \pm 1 \cdot 30$ alleles for tri-nucleotide and $5.60 \pm 1.52$ alleles for tetra-nucleotide repeats.

Using the $F_{\mathrm{ST}}$ outlier approach, one single outlier locus was identified (AAN24A09), which might be a candidate for being subject to selection. The percentage of outlier loci identified was low (4.44\%) but similar to recent studies using amplified fragment length polymorphis (AFLP) scans in lake whitefish Coregonus clupeaformis (Mitchill) and in snail Littorina saxatilis populations that detected $1-5 \%$ of outlier loci (Wilding et al., 2001; Campbell \& Bernatchez, 2004). By contrast, the study of Vasemagi et al. (2005) using EST-linked microsatellites identified a considerably higher number of outlier loci, with nine out of 73 loci (12\%) identified as candidates for being influenced by directional selection. The authors pointed out that a significant deviation from neutral expectations does not demonstrate selection and that subsequent validation is needed, including further sequence analysis. 
Many life-history traits unique to A. anguilla might explain the lack of genetic differentiation between glass eel samples from the Mediterranean and the Atlantic. Firstly, the Sargasso Sea is recognized as the only spawning ground for A. anguilla, based on the discovery by Schmidt (1923) at the beginning of the 20th century of leptocephali (first-stage larvae) near the Sargasso Sea. A recent study placing A. anguilla silver eels in swim tunnels in the laboratory proved that their energy reserves were sufficient to cover the $>5000 \mathrm{~km}$ migration to the Sargasso Sea (van Ginneken et al., 2005). Philopatry to a single spawning ground could explain the genetic homogeneity found in this study, since individuals caught in distant European areas could have the same origin and belong to the same genetic pool. A similar situation has been observed in other marine fishes showing a highly migratory behaviour and philopatry to a single spawning site, such as swordfish Xiphias gladius L. or tunas Thunnus spp. (Pujolar et al., 2002; 2003).

While the existence of a putative spawning site for A. anguilla in the Mediterranean has been discussed throughout the last century (Grassi, 1896; Harding, 1985), the present data do not support this hypothesis: if Mediterranean A. anguilla were spawning in an exclusive site and showing a high fidelity to this site, genetic differences would be expected to accumulate in time in comparison with Atlantic $A$. anguilla, which contradicts the homogeneity in genetic composition found between geographic regions.

The long migration loop observed in A. anguilla gives great opportunity for mixing of individuals at the larval stage during the migration from the Sargasso Sea spawning grounds to the European continental shelf. Calculation of the genetic relatedness among individuals in the present study showed that A. anguilla glass eel arrival waves are composed of $c$. 1-3\% highly related individuals (half sibs or full sibs) plus a majority of unrelated individuals. Mixing of individuals might be accentuated in northern Europe. Boetius \& Boetius (1989) showed that A. anguilla glass eels in northern Europe do not ascend the rivers directly but are forced to stay offshore for a period of $c .3$ months (Desaunay \& Guerault, 1997), which could increase the mixing of individuals before moving into estuarine waters. Relatively continuous recruitment in the Mediterranean (Boetius \& Boetius, 1989) might contribute to mixing of individuals in southern Europe.

The migration loop of $A$. anguilla also provides great opportunity for adults of different ages and different continental sites to mix during the spawning migration back to the Sargasso Sea. Spawning cohorts are expected to be highly mixed as a consequence of the large variance in age at maturity observed in A. anguilla, which ranges from 3 to 25 years, but varies according to sex (on average 8 years in males, 11 years in females), latitude (the A. anguilla life cycle is shorter for populations in the southern part of their range compared to the north because of longer growing seasons), ecosystem characteristics and density-dependent processes (Tesch, 2003). Moreover, the onset of migration can be quite variable from site to site as a consequence of the lunar phase and local meteo-climatic and physical-chemical conditions such as cloud cover, wind intensity and direction, water salinity, rainfall or spate flows (Desaunay \& Guerault, 1997; Tesch, 2003).

One trait that might promote genetic differentiation among sub-populations is that A. anguilla exhibits a protracted spawning season, with field studies suggesting that spawning is restricted to a few months in late winter and spring, while otolith studies of $A$. anguilla glass eel imply that spawning occurs almost all throughout the year 
(McCleave, 2008). Consequently, individuals from geographically separated regions might differ in arrival time at the Sargasso Sea inducing a separation in time of spawning groups. A population structure following an IBT can arise in populations composed of individuals reproducing at different times within a given spawning season. When reproductive times are highly heritable, a restriction in gene flow might occur between early and late spawners, generating a pattern of IBT (Hendry \& Day, 2005). In this sense, the recent study by Maes et al. (2006) reported a subtle IBT pattern which was observed between years, namely between cohorts differing by 2-3 years, but not within years; when testing for IBT within reproductive seasons, temporal distance showed no correlation with genetic distance and samples from comparable sampling dates did not cluster together. Similarly, the analysis of multiple A. anguilla glass eel arrival waves collected during the year in three recruitment sites (North Sea, Bay of Biscay and Mediterranean Sea) showed a lack of seasonal IBT at both allozyme and microsatellite loci (Pujolar et al. 2006, 2007). This would suggest that there is no detectable heritable component in the spawning time within the reproductive season of $A$. anguilla. Nevertheless, it must be taken into account that all studies testing IBT on A. anguilla have included samples from the main arrival peak of glass eels, thus a more extensive sampling covering early and late larval arrivals is needed to test the heritable component of reproduction times.

In addition to a possible seasonal separation, a putative separation in space of spawning groups might also be plausible due to the vastness of the Sargasso Sea (c. $1000 \mathrm{~km}$ wide $\times 3000 \mathrm{~km}$ long), although it has been proposed that distinct temperature fronts may be used as cues to locate specific areas that might facilitate mating and help place larvae in the appropriate currents (McCleave, 1993). Wirth \& Bernatchez (2001) observed a pattern of IBD in a study comparing 13 samples collected throughout Europe using seven microsatellite loci. The IBD pattern was explained by a delay between the arrival of adults from different latitudes at the common spawning site reinforced by non-random return of larvae to the parental original ocean basin. Similarly, the modelling study of Kettle \& Haines (2006) proposed that the success of larvae in crossing the Atlantic Ocean and reaching particular regions of Europe and North Africa might depend strongly on starting point in the Sargasso Sea. Nevertheless, the sampling scheme in Wirth \& Bernatchez (2001) included fish of different ages, namely glass eels from the Mediterranean Sea and yellow or silver eels from northern Europe. Thus the IBD pattern found might result from genetic differences between age groups rather than a true IBD. Similarly, the IBD pattern observed in the study of Maes \& Volckaert (2002) using allozymes was due to one single sample from Italy that differed in age from all other sampled A. anguilla in the study. The study of Dannewitz et al. (2005), the most extensive genetic study in terms of spatial and temporal sampling (2626 individuals collected in 41 locations across Europe including temporal replicates at 12 of those sites) albeit using a limited number of microsatellites, established that occasional differences among geographical samples are not consistent over time. When accounting for temporal genetic variation, no correlation was found between genetic distance and distance to the Sargasso Sea or geographical distance between pairs of samples, and hence no IBD.

Despite the circulation patterns and oceanic currents being complex and still poorly understood, it is well-documented that most larvae cross the Atlantic Ocean following the Gulf Stream and the North Atlantic Current for a journey estimated between 9 months and 2-3 years depending on the methods used to compute it, with the main 
bulk of larvae arriving in the Bay of Biscay area (Lecomte-Finiger, 1994; Arai et al., 2000; Kettle \& Haines, 2006; McCleave, 2008; Bonhommeau et al., 2008a, 2009). The observation of a highly significant heterogeneity in size and condition between western Mediterranean and North Atlantic samples (Boetius \& Boetius, 1989; Pujolar et al., 2006), led to the suggestion of a different migration route that might account for the smaller size of Mediterranean larvae. As the Gulf Stream turns into the North Atlantic Current, a second branch (the Azores Current) first flows south-east towards the mid-Atlantic ridge, then eastwards towards the Gulf of Cadiz, where some of its water is entrained in the outflow of Mediterranean water at Gibraltar (Mann, 1967; Johnson \& Stevens, 2000). A shorter transatlantic journey for Mediterranean larvae was also indicated by the modelling study of Kettle \& Haines (2006).

Morphometric heterogeneity in size and condition between Mediterranean and North Atlantic A. anguilla contrasts with the lack of genetic differentiation observed in the present study, in which Mediterranean and Atlantic samples were compared using the largest number of microsatellite loci to date. In accordance with Dannewitz et al. (2005), this seems to suggest that any temporal or geographic separation of individuals that might occur in the Sargasso Sea is not reinforced by larval homing to the parental original freshwater habitat and, that larval migratory routes are random.

The long spawning migration from Europe to the Sargasso Sea and the mating and spawning process are all under the influence of oceanic factors and climate variation, including large-scale environmental fluctuations like the North Atlantic Oscillation (NAO) (Knights, 2003; Pujolar et al., 2006; Friedland et al., 2007; Bonhommeau et $a l ., 2008 a, b)$. The unpredictability associated with reproduction in the marine environment might result in a large variance in the contribution of individuals to each cohort. Hedgecock (1994) proposed that random events determine which adults are successful in each spawning event, in which many individuals fail to contribute to recruitment and a small fraction of individuals replaces the entire population by a sweepstakes-chance matching of reproductive activity with oceanic conditions.

The genetic consequences of the variation in reproductive success of adults attributable to spatio-temporal variation in oceanographic conditions within and among seasons are a reduction in the effective population size, and a pattern of temporal genetic patchiness (unpatterned genetic heterogeneity) among local populations on a small spatial scale. In this sense, the present study shows a subtle signature of genetic patchiness after detecting a small but significant genetic differentiation $\left(F_{\mathrm{ST}}=0.00241 ; P<0.05\right)$ among samples. The degree of genetic differentiation is similar to previous microsatellite studies, $F_{\mathrm{ST}}=0.0017$ (Wirth \& Bernatchez, 2001), $F_{\mathrm{ST}}=0.0014$ (Dannewitz et al., 2005) or $F_{\mathrm{ST}}=0 \cdot 0018$ (Maes et al., 2006). The observation of a small-scale pattern of genetic patchiness among arrival waves within geographic regions does not conflict with the lack of largescale geographic sub-structuring found between the Mediterranean and Atlantic regions, and is most likely a consequence of the extensive migration loop of $A$. anguilla and the high dependence on oceanic conditions, resulting in a limited (finite) parental contribution to each spawning event. Since genetic relatedness is an indication of the family structure of the larval pools, the observation in the present study of a small but significant percentage of highly related individuals including half and full siblings would support the hypothesis of a patchiness pattern generated by (1) a sweepstakes-matching of the reproduction of a small fraction of the population with oceanic conditions linked to spawning, fertilization, larval 
survival, migration pathways and recruitment, and (2) a low chance of encountering of individuals in time and space in the Sargasso Sea. As a consequence, the results from the present study provide compelling evidence of panmixia in A. anguilla across Europe.

This work has been funded by an Italian Research Program grant to LZ (PRIN 2006, National co-ordinator G. De Leo) and by the University of Padova grant CPDA 085158/08 to L.Z. (Ateneo Project 2008). We thank C. Briand (Institution d'Aménagement de la Vilaine) and G. Castelnaud (CEMAGREF Bordeaux) for providing samples.

\section{References}

Antao, T., Lopes, A., Lopes, R. J., Beja-Pereira, A. \& Luikart, G. (2008). LOSITAN- A workbench to detect molecular adaptation based on a $F_{\mathrm{ST}}$-outlier method. BMC it Informatics 9, 323.

Arai, T., Otake, T. \& Tsukamoto, T. (2000). Timing of metamorphosis and larval segregation of the Atlantic eels Anguilla rostrata and A. anguilla, as revealed by otolith microstructure and microchemistry. Marine Biology 137, 39-45.

Belkhir, K., Borsa, P., Goudet, J. \& Bonhomme, F. (2005). GENETIX 4.05: Logiciel sous Windows pour la Genetique des Populations. Montpellier, France: Laboratoire Genome \& Population, CNRS-UPR, Universite de Montpellier II.

Boetius, I. \& Boetius, J. (1989). Ascending elvers, Anguilla anguilla, from 5 European localities. Analyses of pigmentation stages, condition, chemical composition and energy reserves. Dana 7, 1-12.

Bonhommeau, S., Chassot, E. \& Rivot, E. (2008a). Fluctuations in European eel (Anguilla anguilla) recruitment resulting from environmental changes in the Sargasso Sea. Fisheries Oceanography 17, 32-44.

Bonhommeau, S., Chassot, E., Planque, B., Rivot, E., Knapp, A. H. \& Le Pape, O. (2008b). Impact of climate on eel populations of the Northern Hemisphere. Marine Ecology Progress Series 373, 71-80.

Bonhommeau, S., Le Pape, O., Gascuel, D., Blanke, B., Tréguier, A. M., Grima, N., Vermard, Y., Castonguay, M. \& Rivot, E. (2009). Estimates of the mortality and the duration of the trans-Atlantic migration of European eel Anguilla anguilla leptocephali using a particle tracking model. Journal of Fish Biology 74, 1891-1914.

Campbell, D. \& Bernatchez, L. (2004). Genomic scan using AFLP markers as a means to assess the role of directional selection in the divergence of sympatric whitefish ecotypes. Molecular Biology and Evolution 21, 945-956.

Cavalli-Sforza, L. L. \& Edwards, A. W. F. (1967). Phylogenetic analysis models and estimation procedures. Evolution 32, 550-570.

Conover, D. O., Clarke, L. M., Munch, S. B. \& Wagner, G. N. (2006). Spatial and temporal scales of adaptive divergence in marine fishes and the implications for conservation. Journal of Fish Biology 69, 21-47.

Dannewitz, J., Maes, G. E., Johansson, L., Wickstrom, H., Volckaert, F. A. M. \& Jarvi, T. (2005). Panmixia in the European eel: a matter of time. Proceedings of the Royal Society B 272, 1129-1137.

Desaunay, Y. \& Guerault, D. (1997). Seasonal and long-term changes in biometrics of eel larvae: a possible relationship between recruitment variation and North Atlantic ecosystem productivity. Journal of Fish Biology 51, 317-339.

Friedland, K. D., Miller, M. I. \& Knights, B. (2007). Oceanic changes in the Sargasso Sea and declines in recruitment of the European eel. ICES Journal of Marine Science 64, $519-530$.

van Ginneken, V., Antonissen, E., Muller, U. K., Booms, R., Eding, E., Verreth, J. \& Van den Thillart, G. (2005). Eel migration to the Sargasso: remarkably high swimming efficiency and low energy costs. Journal of Experimental Biology 208, 1329-1335.

Grassi, B. (1896). The reproduction and metamorphosis of the European eel (Anguilla vulgaris). Proceedings of the Royal Society 60, 260-271. 
Harding, E. F. (1985). On the homogeneity of the European eel (Anguilla anguilla). Dana 4, 49-66.

Hedgecock, D. (1994). Does variance in reproductive success limit effective population size of marine organisms? In Genetics and Evolution of Aquatic Organisms (Beaumont, A., ed.), pp. 122-134. London: Chapman \& Hall.

Hemmer-Hansen, J., Nielsen, E. E., Frydenberg, J. \& Loeschcke, V. (2007). Adaptive divergence in a high gene flow environment: $\mathrm{Hsc} 70$ variation in the European flounder (Platichthys flesus). Heredity 99, 592-600.

Hendry, A. P. \& Day, T. (2005). Population structure attributable to reproductive time: isolation by time and adaptation by time. Molecular Ecology 14, 901-916.

Johnson, J. \& Stevens, I. (2000). A fine resolution model of the eastern North Atlantic between the Azores, the Canary Islands and the Gibraltar Strait. Deep-Sea Research 47, 875-899.

Kalinowski, S. T., Wagner, A. P. \& Taper, M. L. (2006). ML-Relate: a computer program for maximum estimation of relatedness and relationship. Molecular Ecology Notes 6, $576-579$.

Kettle, A. \& Haines, K. (2006). How does the European eel (Anguilla anguilla) retain its population structure during its larval migration across the North Atlantic Ocean? Canadian Journal of Fisheries and Aquatic Sciences 63, 90-106.

Kettle, A., Bakker, D. C. E. \& Haines, K. (2008). Impact of the North Atlantic Oscillation on the trans-Atlantic migrations of the European eel (Anguilla anguilla). Journal of Geophysical Research 113, GO3004. doi:10.1029/2007JG000589

Knights, B. (2003). A review of the possible impacts of long-term oceanic and climate changes and fishing mortality on recruitment of anguillid eels of the Northern hemisphere. Science of the Total Environment 310, 237-244.

Lecomte-Finiger, R. (1994). The early life of the European eel. Nature 370, 424.

Maes, G. E. \& Volckaert, F. A. M. (2002). Clinal genetic variation and isolation by distance in the European eel Anguilla anguilla. Biological Journal of the Linnean Society 77, $509-522$.

Maes, G. E., Pujolar, J. M., Hellemans, B. \& Volckaert, F. A. M. (2006). Evidence of isolation by time in the European eel (Anguilla anguilla). Molecular Ecology 15, 2095-2107.

Mann, C. R. (1967). The termination of the Gulf Stream and the beginning of the North Atlantic Current. Deep Sea Research 14, 337-359.

McCleave, J. D. (1993). Physical and behavioral controls on the oceanic distribution and migration of leptocephali. Journal of Fish Biology 43, 243-273.

McCleave, J. D. (2008). Contrasts between spawning times of Anguilla species estimated from larval sampling at sea and from otolith analysis of recruiting glass eels. Marine Biology 155, 249-262.

O'Malley, K. G. \& Banks, M. A. (2008). A latitudinal cline in the Chinook salmon (Oncorhynchus tshawytscha) Clock gene: evidence for selection on PolyQ length variants. Proceedings of the Royal Society B 275, 2813-2821.

Pujolar, J. M., Roldan, M. I. \& Pla, C. (2002). A genetic assessment of the population structure of swordfish (Xiphias gladius) in the Mediterranean Sea. Journal of Experimental Marine Biology and Ecology 276, 19-29.

Pujolar, J. M., Roldan, M. I. \& Pla, C. (2003). Genetic analysis of tuna populations Thunnus thynnus thynnus and T. alalunga. Marine Biology 143, 613-621.

Pujolar, J. M., Maes, G. E. \& Volckaert, F. A. M. (2006). Genetic patchiness among recruits of the European eel Anguilla anguilla. Marine Ecology Progress Series 307, 209-217.

Pujolar, J. M., Maes, G. E. \& Volckaert, F. A. M. (2007). Genetic and morphometric heterogeneity among recruits of the European eel Anguilla anguilla. Bulletin of Marine Sciences 81, 297-308.

Pujolar, J. M., Maes, G. E., Van Houdt, J. K. J. \& Zane, L. (2008). Isolation and characterization of EST-linked microsatellite loci for the European eel, Anguilla anguilla. Molecular Ecology Resources 9, 233-235.

Raymond, M. \& Rousset, F. (1995). GENEPOP (version 1.2): a population genetics software for exact tests and ecumenicism. Journal of Heredity 86, 248-249. 
Rice, W. R. (1989). Analyzing tables and statistical tests. Evolution 43, 223-225.

Schmidt, J. (1923). Breeding places and migration of the eel. Nature 111, 51-54.

Schneider, S., Roessli, D. \& Excoffier, L. (2000). ARLEQUIN: a Software for Population Genetics Data Analysis Version 3.0 Geneva, Switzerland: Genetics and Biometry Laboratory, Department Anthropology, University of Geneva.

Tesch, F. W. (2003). The Eel, 3rd edn. Oxford: Blackwell Science Ltd.

Van Oosterhout, C. V., Hutchinson, W. F., Wills, D. P. M. \& Shipley, P. (2004). Microchecker: software for identifying and correcting genotyping errors in microsatellite data. Molecular Ecology 4, 535-538.

Vasemagi, A., Nilsson, J. \& Primmer C. R. (2005). Expressed sequence tag-linked microsatellites as source of gene-associated polymorphisms for signatures of divergent selection in Atlantic salmon (Salmo salar). Molecular Biology and Evolution 22, 1067-1076.

Weir, B. S. \& Cockerman, C. C. (1984). Estimating F-statistics for the analysis of population structure. Evolution 38, 1358-1370.

Wilding, C. S., Butlin, R. K. \& Grahame, J. (2001). Differential gene exchange between parapatric morphs of Littorina saxatilis detected using AFLP markers. Journal of Evolutionary Biology 14, 611-619.

Wirth, T. \& Bernatchez, L. (2001). Genetic evidence against panmixia in European eel. Nature 409, 1037-1040.

Wright, S. (1931). Evolution in Merdelian populations. Genetics 16, 97-159.

\section{Electronic References}

Goudet, J. (2002). FSTAT, a Program to Estimate and Test Gene Diversities and Fixation Indices (v. 2.9.3.2.). Available from http://www2.unil.ch/opgen/softwares/fstat.htm

ICES. (2008). Report of the joint EIFAC/ICES Working Group on Eels (WGEEL), 3-9 September 2008, Leuven, Belgium. ICES CM 2008/ACFM:15. Available at http://www.icesdk/workinggroups/ViewWorkingGroup.aspx?ID=75 